\title{
Dental Stem Cell Migration on Pulp Ceiling Cavities Filled with MTA, Dentin Chips, or Bio-Oss
}

\author{
Stefania Lymperi, ${ }^{1,2}$ Vasiliki Taraslia, ${ }^{2}$ Ioannis N. Tsatsoulis, ${ }^{1}$ \\ Athina Samara, ${ }^{3}$ Athanasios D. Velentzas, ${ }^{4}$ Anastasia Agrafioti, ${ }^{1}$ \\ Ema Anastasiadou, ${ }^{2}$ and Evangelos Kontakiotis ${ }^{1}$ \\ ${ }^{1}$ Department of Endodontics, Dental School, University of Athens, Athens, Greece \\ ${ }^{2}$ Department of Genetics and Gene Therapy, Biomedical Research Foundation of the Academy of Athens, Athens, Greece \\ ${ }^{3}$ University of Oslo, Postboks 1103, Blindern, 0317 Oslo, Norway \\ ${ }^{4}$ Department of Cell Biology and Biophysics, Faculty of Biology, University of Athens, Athens, Greece
}

Correspondence should be addressed to Evangelos Kontakiotis; ekontak@dent.uoa.gr

Received 28 January 2015; Revised 5 May 2015; Accepted 12 May 2015

Academic Editor: Antonio Salgado

Copyright (C) 2015 Stefania Lymperi et al. This is an open access article distributed under the Creative Commons Attribution License, which permits unrestricted use, distribution, and reproduction in any medium, provided the original work is properly cited.

\begin{abstract}
MTA, Bio-Oss, and dentin chips have been successfully used in endodontics. The aim of this study was to assess the adhesion and migration of dental stem cells on human pulp ceiling cavities filled with these endodontic materials in an experimental model, which mimics the clinical conditions of regenerative endodontics. Cavities were formed, by a homemade mold, on untouched third molars, filled with endodontic materials, and observed with electron microscopy. Cells were seeded on cavities' surface and their morphology and number were analysed. The phenomenon of tropism was assessed in a migration assay. All three materials demonstrated appropriate microstructures for cell attachment. Cells grew on all reagents, but they showed a differential morphology. Moreover, variations were observed when comparing cells numbers on cavity's filling versus the surrounding dentine disc. The highest number of cells was recorded on dentin chips whereas the opposite was true for Bio-Oss. This was confirmed in the migration assay where a statistically significant lower number of cells migrated towards Bio-Oss as compared to MTA and dentin chips. This study highlights that MTA and dentin chips have a greater potential compared to Bio-Oss regarding the attraction of dental stem cells and are good candidates for bioengineered pulp regeneration.
\end{abstract}

\section{Introduction}

The treatment of pulpal necrosis of an immature tooth with an open apex has been traditionally achieved using either long term calcium hydroxide $\left[\mathrm{Ca}(\mathrm{OH})_{2}\right]$ apexification procedures, or more recently the MTA apical barrier technique $[1,2]$. Despite the high success rate of those treatments, further root development did not usually occur and the roots remained thin, fragile, and prone to fracture $[2,3]$. Thus, new therapeutic approaches are imperative, including dental regenerative technologies.

Regenerative endodontics are referred to as biologically based procedures which aim to replace diseased, damaged, or missing structures such as dentin, root structures, and cells of the pulp-dentin complex [4]. Early experiments demonstrated the essential role of blood clot and the revascularization which provides blood supply to existing pulp tissue for subsequent completion of root development [5]. Other contributing factors are the progress in stem cell research and particularly the discovery of dental stem cells and their potential therapeutic applications on tissue engineering $[6$, 7].

Current studies reported the revascularization of root canals in necrotic teeth, following disinfection using antibiotics and mechanical irritation to initiate bleeding into the canal so that a blood clot would be formed at the level of cementoenamel junction. In most of these cases, mineral trioxide aggregate (MTA) was applied to seal the blood clot despite the initial difficulties to be stabilized on top of the clot $[8,9]$. In fact, MTA has been used in numerous 
studies as a sealing pulp space barrier material in regenerative endodontics procedures [10,11]. The main advantages of MTA are high biocompatibility, lack of cytotoxicity and carcinogenicity, antibacterial action, good sealing capacity, and radiopacity [12-14]. Furthermore, it has been shown to allow the adherence and proliferation of osteoblasts on its surface, whereas clinical studies have demonstrated that MTA could be used as a root-end filling material [15-17].

Bio-Oss is a natural, nonantigenic, porous bone mineral matrix, produced by the removal of all organic components of bovine bone. Due to its natural and chemical similarities with the human bone, it has been used in clinical practice for many years with beneficial results [18-20]. Furthermore, Bio-Oss facilitates the absorption of blood and favours the formation of vasculature due to its trabecular architecture, interconnecting macro- and micropores and its natural consistency $[21,22]$. Moreover, the structure of Bio-Oss favours the migration of cells through its matrix [23].

Dentin chips, on the other hand, have been applied in a number of in vitro and in vivo studies [24-30]. This material is not commercially available and for its preparation human teeth are autoclaved and crushed into chips. The presence of dentin promotes the formation of a calcified tissue similar to ossein and accelerates healing whilst inhibiting inflammatory reaction $[25,31]$.

The aim of the present study is to evaluate the ability of dental stem cells extracted from Human Exfoliated Deciduous Teeth (SHEDs) to adhere, grow, and migrate on the dental pulp cavities of molars that have been filled with MTA, BioOss, or dentin chips.

The advantage of our approach is that it directly compares these three reagents in a setting that simulates the clinical conditions and includes MTA, an extensively used dental reagent, as well as Bio-Oss and dentin chips that could possible serve as alternative materials for pulp space barrier sealing.

\section{Materials and Methods}

2.1. MOLAR Pulp Wall Processing. An in vitro experimental model aiming to recapitulate the clinical conditions was generated in order to study the effect of three dental materials on dental mesenchymal stem cells. Twenty untouched third lower molars recently were extracted (within less than 3 months) from individuals of 20-40 years of age and each one was freshly used for the experimental assays. Each molar was cut $1 \mathrm{~mm}$ above the cementoenamel junction (CEJ), using a blade (Hopf, Ringleb \& Co., Gmbh and Cie, Berlin, Germany) and abundance of water spray. A cavity was prepared using a handmade metal triangular base with $3 \times$ $4 \times 4 \mathrm{~mm}$ dimensions and $2 \mathrm{~mm}$ thickness. The processed samples were autoclaved and the formed cavities were filled with the different reagents. The thickness of the filling was controlled by the metal triangular construction, in a way that $1 \mathrm{~mm}$ of free space was formed around the cavities of the pulp wall. MTA (Dentsply Tulsa Dental Specialties, Memphis, TN) and Bio-Oss (Geistlich AG, Wolhusen, Switzerland) were prepared according to the manufacturer's instructions and five formed cavities per material were filled with the different reagents. Five samples were also filled with dentin chips and five samples were used as controls (tooth without any material) (Figure 1).

2.2. Dentin Chips Preparation. The crowns of ten human third molars recently extracted from individuals aged 20-40 years were autoclaved and processed as previously described [26]. Dentin chips were prepared using an autoclaved round bur US 7 RAL (Hager and Meisinger, Germany) of $2 \mathrm{~mm}$ diameter placed on an autoclaved glass slide without water spray and with low-speed handpiece.

2.3. Cell Culture. Stem cells from Human Exfoliated Deciduous Teeth (SHEDs) were provided by ProCell, Biotechnological Application SA (Athens, Greece). A $100 \mu \mathrm{L}$ drop of $10^{5}$ live SHEDs cell suspension was carefully placed on top of each sample and cultured for 3 days in Dulbecco's Modified Eagle's Medium (DMEM, Gibco, Glasgow, UK), supplemented with sodium pyruvate, streptomycin, penicillin, and L-glutamine and complemented with $10 \%$ heat-inactivated fetal bovine serum (FBS, Biowest) at $37^{\circ} \mathrm{C}$ in a $5 \% \mathrm{CO}_{2}$ humidified incubator. Cells were used between the third and fifth passage.

2.4. Cell Counting. Cells cultured on the surface of the samples were fixed in 4\% PFA for 20 minutes at room temperature, followed by PBS washing. The samples were then stained using Phalloidin-Rhodamine solution (Molecular Probes) at $37^{\circ} \mathrm{C}$ to stain the cytoskeleton and more specifically the actin filaments. $4^{\prime}, 6$-Diamidino-2-phenylindole (DAPI) was also used for the detection of the nucleus. Samples were placed on top of a microscope slide with Vectashield (VECTOR Laboratories, Peterborough, UK) and observed under the confocal microscope Leica TCS SP5 (Leica, Wetzlar, Germany) in a $20 \mathrm{x}$ resolution and analysed using the Leica software, LAS AF. The whole surface of the samples was scanned under the confocal microscope and particularly the area where the different materials were in direct contact with the dentin of the pulp wall. At least five different equally sized areas were carefully observed for each sample and the cells attached on the tooth and the material were recorded and enumerated.

2.5. Electron Microscopy. The surface structural organization of each specimen was examined through a scanning electron microscopy (SEM) approach. Samples were attached on aluminum stubs, coated with gold/palladium in a sputtercoating apparatus (Tousimis Samsputter-2a, Rockville, Maryland, USA), for $2 \mathrm{~min}$ and visualized under a Philips SEM 515 scanning electron microscope.

2.6. Migration Assay. MTA, Bio-Oss, and dentin chips were prepared as previously described according to the manufacturer's instructions in 24-well plates and allowed to set overnight. SHEDs were cultured in serum-free DMEM for 2 hours prior to being plated to the upper chamber of the transwells. $25 \times 10^{3}$ cells $/ \mathrm{mL}$ were seeded within $100 \mathrm{~mL}$ of media into the upper compartment of a $6 \mathrm{~mm}$ diameter migration chamber, composed of a polycarbonate filter with $8 \mathrm{~mm}$ pores (Costar Transwell; Corning Inc., Corning, NY) 


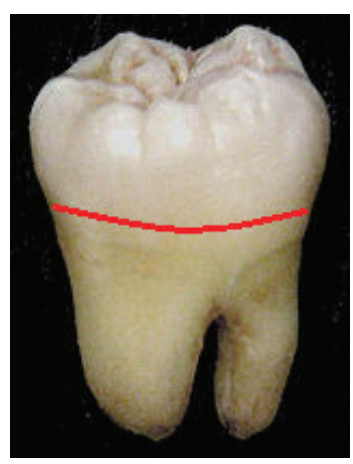

Tooth

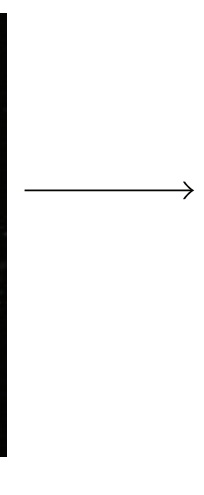

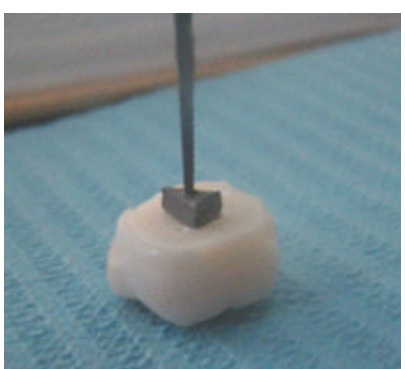

Pulp chamber ceiling
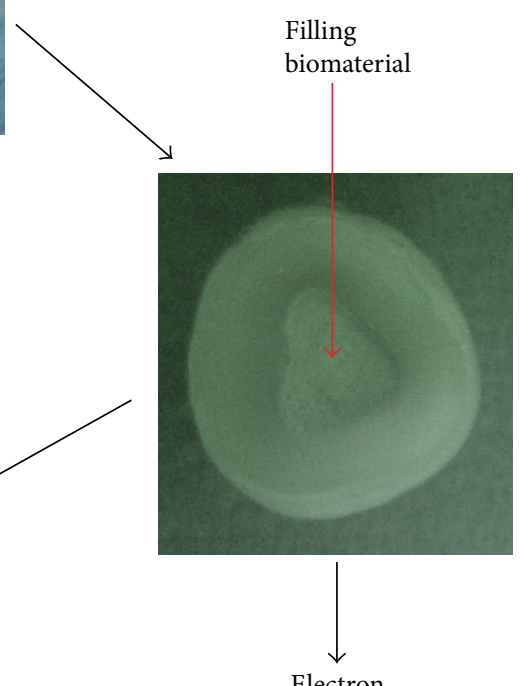

Electron

microscopy

FIGURE 1: Experimental strategy. A tooth slice is prepared by removing the root of third molars and a canal is formed by using a handmade metal base. The root canal is filled with a reagent commonly used in endodontics such as MTA, Bio-Oss, or dentin chips; electron microscopy was performed to assess their surface morphology. The different materials were seeded with dental mesenchymal stem cells, cultured for 72 hours and studied by confocal microscopy; the state and the number of the cells were recorded and further analyzed.

that was prewarmed at $37^{\circ} \mathrm{C}$. The cells were cultured and allowed to migrate for 6 hours at $37^{\circ} \mathrm{C}$ in a moist environment and $5 \% \mathrm{CO}_{2}$. The upper chamber containing the filter was removed. The nonmigrating cells attached to the upper side of the filter were carefully removed with a cotton swab and the cells were fixed with $1 \%$ paraformaldehyde for 15 minutes at room temperature and rinsed twice with PBS. The migrating cells attached to the lower side of the filter were stained with $0.1 \%$ crystal violet (prepared in $10 \%$ ethanol) for 15 minutes at room temperature, washed with $\mathrm{dH}_{2} \mathrm{O}$, and airdried overnight. Five brightfield micrographs per sample, at 20x magnification, were randomly chosen, in order to count the migrated cells using the cell-counted plug-in of ImageJ. Results from two different experiments were expressed as mean \pm SD.

2.7. Statistical Analysis. Statistical analysis was performed using one-way repeated analysis of variance (ANOVA). Additionally, simple univariate analysis of variance was used along with Tukey post hoc test to specify statistically significant differences, investigating all pairwise differences. For all tests, the level of statistical significance was set at $5 \%$.

\section{Results}

Untouched third molars were extracted and decoronated and a cavity was made with a homemade mold as demonstrated in Figure 1. The cavities were filled with endodontic materials and, once set, cells were seeded on these surfaces and their morphology and number were analysed (Figure 1). Scanning electron microscopy (SEM) was used to study the microstructure of the MTA, dentin chips, and Bio-Oss after setting. All materials possess microstructures offering a rough surface sufficient for the viability and adhesion of dental mesenchymal stem cells (Figure 2(a)). As shown in Figure 2(a), the material with the highest porosity was the dentin chips, when compared to MTA and Bio-Oss.

Regarding cell growth and morphology, cells on MTA demonstrated a typical fibroblast-like polarized appearance with elongated cytoskeleton, whereas cells on dentin chips showed similar profile but milder spindle-shape formation (Figure 2(b)). Bio-Oss seemed to dramatically affect the cell distribution and morphology as it appeared to form compact clusters and abolished their spindle-shape appearance, becoming thus smaller and rounder with dense cytoplasm.

To further study dental mesenchymal stem cells in the presence of the three reagents, cells were counted in three independent experiments for each material. The analysis revealed that even though the total number of cells attached to the dental discs filled with the different materials was not statistically different among the three substrates, some materials favored the adherence and growth of dental mesenchymal stem cells on these substrates, compared to others (Figure 3(a)). More specifically, a statistically significant higher number of dental mesenchymal stem cells were found on the surface of the filling when dentin chips were analysed 

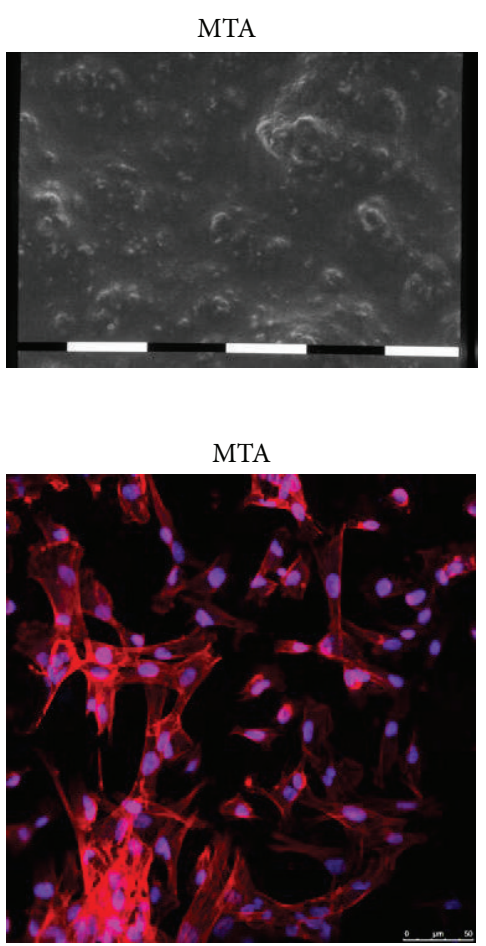

Bio-Oss

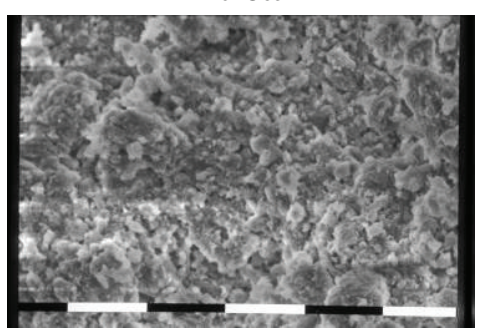

(a)

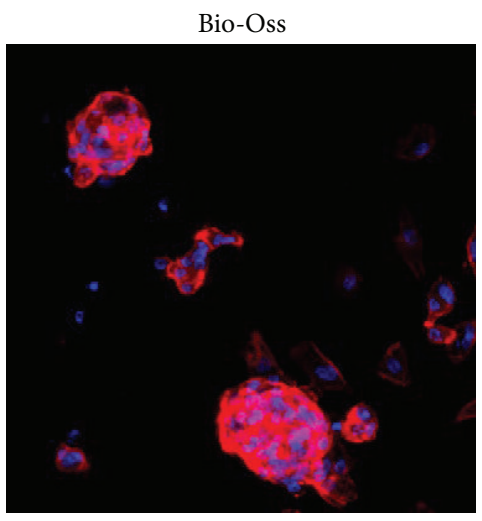

(b)
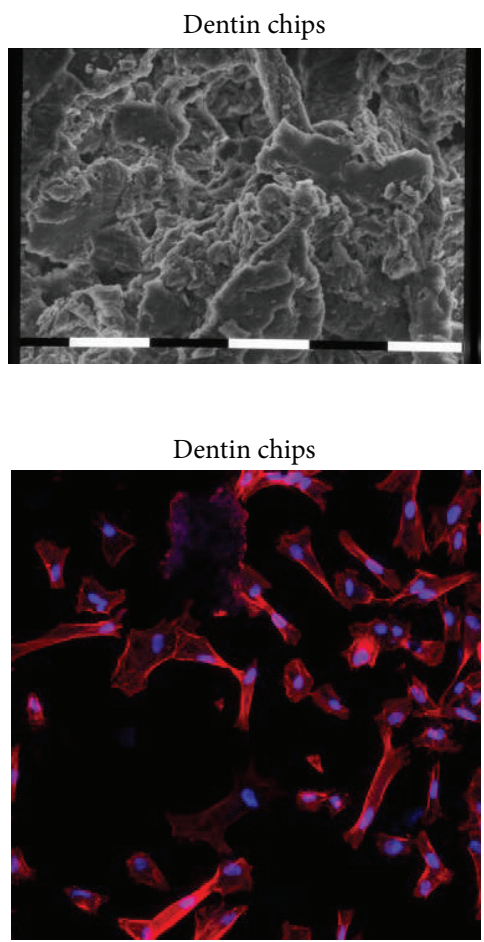

Figure 2: (a) The surface structural organization of each specimen was examined by scanning electron microscopy (magnification $\times 2200$ ). All three reagents, MTA, Bio-Oss, and Dentin chips, offer rough surface which is adequate for cell adhesion with dentin chips showing the highest degree of coarseness followed by Bio-Oss. (b) Representative images of the cell cultures on the surface of the different dental substances by confocal microscopy. The cells were cultured for 72 hours on the provided specimens and fixed and stained with Phalloidin to depicture the cytoskeleton of the dental mesenchymal stem cells (red) and DAPI for the nucleus (blue). The morphology and the clustering of the cells vary according to the applied material.

(One-way ANOVA, $p=0.009$ ). The opposite was true for the Bio-Oss, where a statistically significant higher number of cells were found on the tooth versus the filling material $(p=0.005)$. No major differences were observed for MTA, as there was an equal distribution of cells on top of the tooth and on top of the filling $(p=0.252)$ (Figure $3(\mathrm{~b})$ ).

As the total number of cells on the dental discs is the same regardless of the different cavity filling material, it seems likely that these endodontic reagents did not demonstrate cytotoxic effects and, therefore, no major cell death or proliferation arrest was observed. This finding, in combination with the material surface SEM micrographs that demonstrated rough surfaces suitable for cell adhesion, suggests that cells might exhibit differential migratory capacity upon adherence. Indeed the above finding was further supported by the results obtained from migration assays. The three different materials were plated on migration chambers to assess whether the difference observed in the previous experiments was due to the phenomenon of tropism or taxis (Figure 4). A statistically significant higher number of cells migrated through the transwell filter when dentin chips were added in the migration chamber compared to all the other materials. Moreover, a statistically significant lower number of cells migrated through the transwell filter when Bio-Oss was added in the migration chamber compared to all the other materials. Overall, dentin chips favored the migration of cells compared to the other materials, whereas Bio-Oss inhibited the migration of dental mesenchymal stem cells as compared to MTA and dentin chips (Figure 4).

\section{Discussion}

The study of the dental stem cells responses on different substrates that could potentially be used as scaffolds for dental tissue bioengineering is fundamental for the new emerging field of regenerative endodontics. We have previously shown that ProRoot MTA is the most biocompatible material to Periodontal Ligament Fibroblasts (PDL) regarding root-end endodontic microsurgery [13]. In the current study, we have taken our research one step further by investigating the impact of the direct contact of materials that have been used both in conservative dentistry and in surgical endodontics on dental mesenchymal stem cells. Therefore, we compared MTA, a substrate traditionally used as a ceiling material in regenerative endodontics, to Bio-Oss and dentin chips, assessing whether the use of the latter could possibly serve better this role.

A successful scaffold in regenerative medicine should allow for attachment and provide the mechanical support to the cells, favouring their migration whilst enabling the 


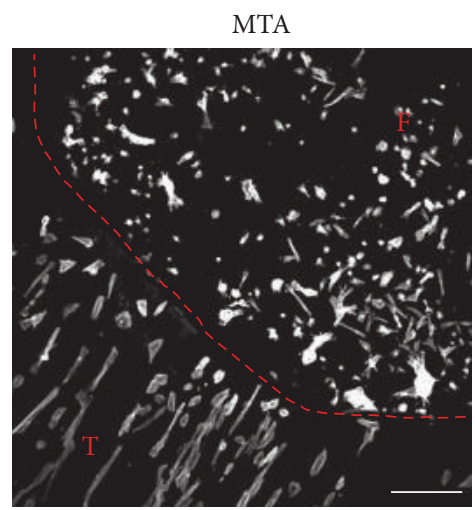

(i)

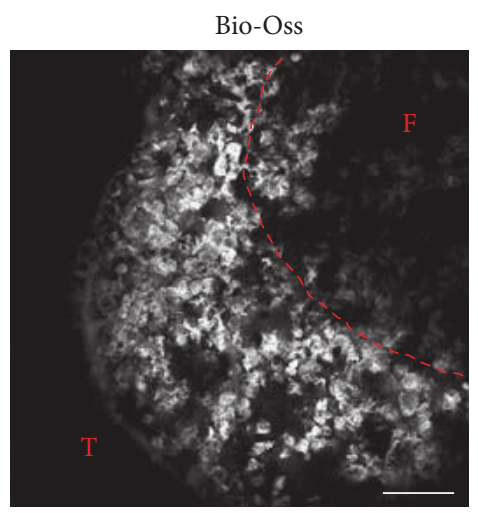

(ii)

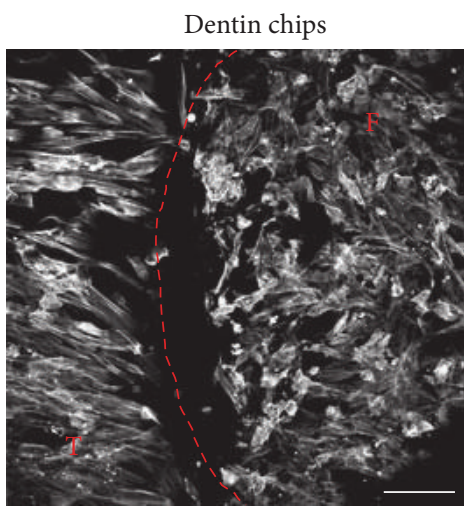

(iii)

(a)

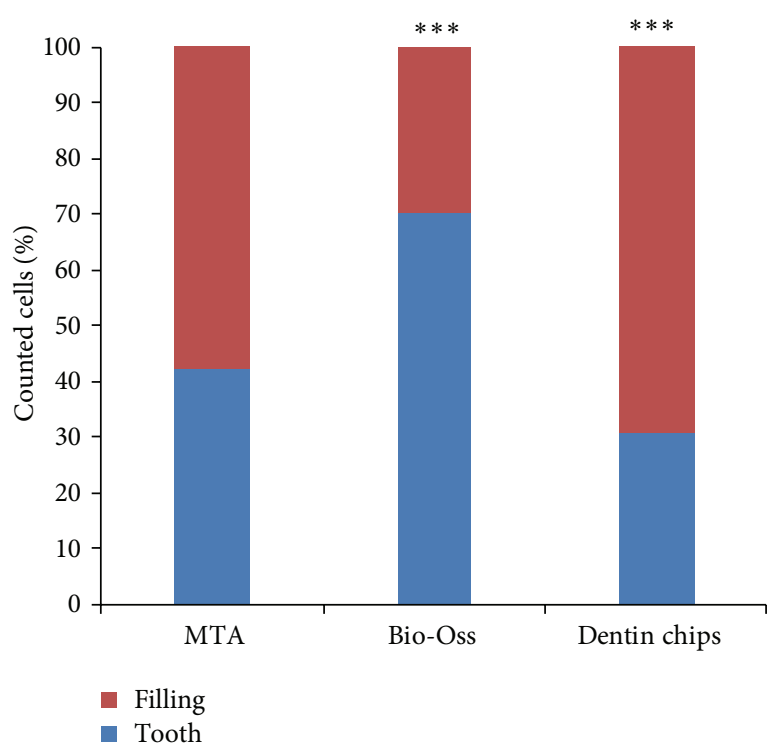

(b)

Figure 3: (a) Confocal images of cells showing their growing and distribution on the tooth surface and on the different root filling dental materials. (i) MTA, (ii) dentin chips, and (iii) Bio-Oss; white: Phalloidin, Bar corresponds to $250 \mu \mathrm{m}$, T: tooth, F: filling. (b) The graph represents the percentage distribution of dental mesenchymal stem cell cultures on top of the tooth and the different filling materials. A statistically significant higher number of cells were found on dentin chips, while the opposite was true for Bio-Oss and equal distribution of the cells was observed for MTA. ${ }^{* * *} p<0.005$.

circulation of biochemical factors and vital cell nutrients [4]. It is known that the effectiveness of a scaffold depends on the pore distribution, its exposed surface area, and its porosity [4]. We demonstrated by electron microscopy that all the materials analyzed in this study form a porous surface and appropriate microstructures for the attachment of cells with dentin chips exhibiting the highest porosity. This is in agreement with our finding that dentin chips provide better support to the dental mesenchymal stem cells at least when the number of cells populating this material is used as the experimental readout.

It has been previously suggested that contact of dental materials with the dentine wall may alter their properties [26]. Therefore, to overcome this limitation, we generated a model where the dental materials (MTA, Bio-Oss, and dentin chips) are in direct contact with pulp ceiling simulating the actual situation of the clinical praxis in endodontics. This in vitro experimental model has a number of advantages, such as the use of freshly extracted third molars, avoiding unknown conditions due to long-term storage, affecting dentin, and dental pulp cavity. Moreover, by using a handmade metal base to create the dental cavity on the dental discs, we were able to assure the homogeneity of our samples allowing our findings to be directly comparable to each other.

Using the above strategy, we demonstrated that dental mesenchymal stem cells were able to grow on the dental pulp cavity and in direct contact with all the filling materials used. This is in agreement with the previously published literature where it has been shown that human osteosarcoma cell lines, osteoblasts [16], bone marrow derived mesenchymal 


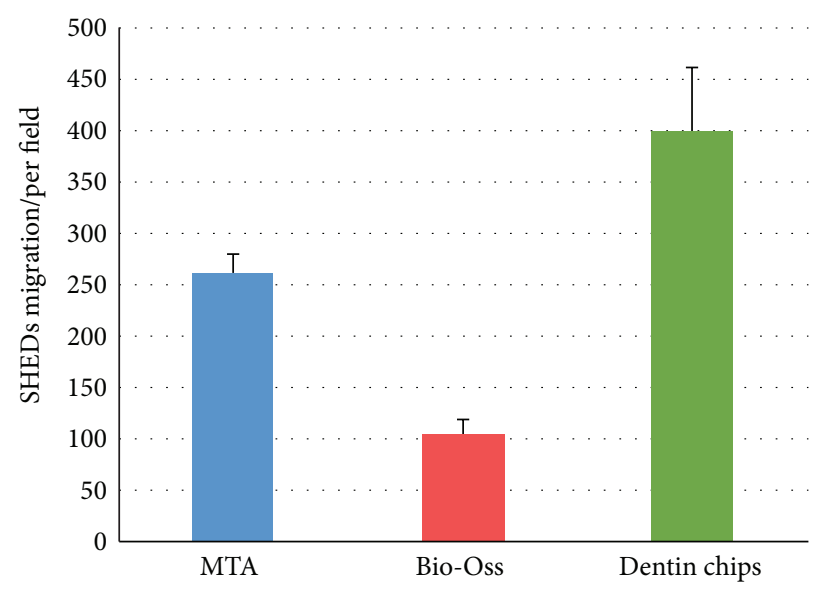

(a)
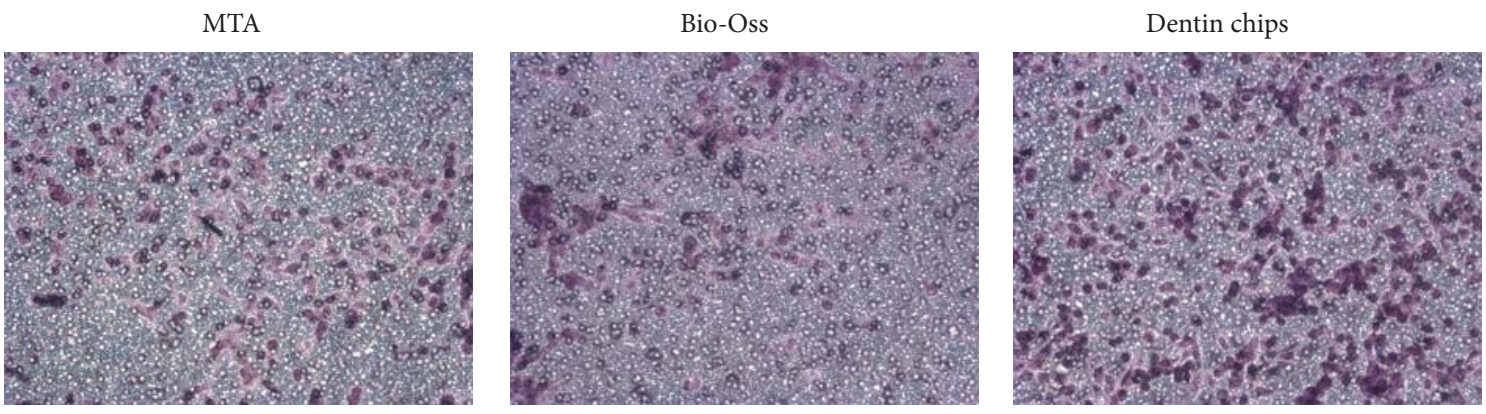

(b)

FIGURE 4: (a) Mean dental mesenchymal stem cell migration in response to the different materials. Error bars represent the standard deviation. ${ }^{* * *} p<0.005$. (b) Light microscope images at 20x magnification. The cells were fixed and stained with crystal violet to reveal their numbers and position as the cells become purple in the presence of the dye.

stem cells [32], and human tooth germ cells [33] are able to adhere and grow on MTA and similarly osteoblasts [34], mesenchymal stem cells from peripheral blood [35], or mesenchymal stem cells from bone marrow [36] can grow on Bio-Oss. Moreover, in the present study, we were able to directly compare the three materials and demonstrate for the first time that dental stem cells seemed to prefer dentin chips and MTA as opposed to Bio-Oss. In fact, as the oneway ANOVA analysis demonstrated, a statistically significant higher number of cells were found attached on dentin chips compared to the dental disc.

To further elaborate on the mechanism of this finding, we studied the cell migration towards the different materials through a transwell filter. We demonstrated that in $24 \mathrm{~h}$ both MTA and dentin chips attract dental mesenchymal stem cells, whereas Bio-Oss seems to inhibit their migration through the filter. Our results, regarding MTA, are in accordance with the current literature as it was previously shown that MTA promotes stem cell migration [32] and that in the presence of MTA undifferentiated dental pulp stem cells upregulated the expression of genes involved in cell migration [37]. Regarding the dentin chips, it is possible that fresh dentin chips which include organic substances [28] provide nutrients and growth factors that are important for the adherence and migration of the dental stem cells.
On the contrary, Bio-Oss exhibited the poorest supporting capacity, changing their morphology to cluster formations. Given that Bio-Oss has a bovine origin [38], there might be an incompatibility issue as SHEDs are derived from human teeth. In fact, our data show that human mesenchymal stem cells perform better on human versus bovine dental discs (see Supplementary Figure in Supplementary Material available online at http://dx.doi.org/10.1155/2015/189872). Finally, MTA which is composed of inorganic materials [39] was found to preserve the morphology of dental mesenchymal stem cells and favor their adherence and growth. Further investigation needs to be performed to identify the exact molecular mechanisms that dictate the cell growth, migration, and morphology in the presence of the different dental material.

Briefly, in this comparative study and in our experimental setup, we demonstrated that dentin chips act as a superior to MTA material in regenerative endodontic procedures, promoting the adhesion and migration of dental pulp derived stem cells. However, the result of our in vitro studies is not easily applied in everyday clinical practice, as dentin chips are not currently commercially available. Therefore, issues of reproducible quality of the material as well as sterility and availability of the reagent should be raised. Moreover, the dentin chips preparation used throughout this study cannot be polymerized in its present form and consequently it cannot 
be the solid and robust sealer which once placed on top of the blood clot will form a pulp space barrier securing the dental cavity.

\section{Conclusion}

In conclusion, we demonstrated that Bio-Oss is not performing as well as MTA with respect to the adhesion and migration of dental stem cells, while dentin chips were proved to be the best performing reagent in our experimental setting. This interesting finding should be taken under serious consideration when decisions regarding root filling materials are made. Further research will serve to delineate the physiology behind these findings and their applications in regenerative endodontic procedures.

\section{Conflict of Interests}

The authors deny any conflict of interests.

\section{Authors' Contribution}

Stefania Lymperi designed, performed, and analyzed experiments and wrote the paper, Ioannis N. Tsatsoulis performed experiments, Vasiliki Taraslia performed and analyzed experiments, Athina Samara performed experiments, Athanasios D. Velentzas performed experiments, Anastasia Agrafioti revised the paper, Evangelos Kontakiotis designed experiments and revised the paper, and Ema Anastasiadou designed and analyzed experiments and wrote the paper. Stefania Lymperi and Vasiliki Taraslia contributed equally.

\section{Acknowledgments}

The research project is implemented within the framework of the Action "Supporting Postdoctoral Researchers" of the Operational Program "Education and Lifelong Learning" (Funding Authority: General Secretariat for Research and Technology) and is cofinanced by the European Social Fund (ESF) and the Greek State.

\section{References}

[1] M. Cvek, "Treatment of non-vital permanent incisors with calcium hydroxide. I. Follow-up of periapical repair and apical closure of immature roots," Odontologisk Revy, vol. 23, no. 1, pp. 27-44, 1972.

[2] D. T. Holden, S. A. Schwartz, T. C. Kirkpatrick, and W. G. Schindler, "Clinical outcomes of artificial root-end barriers with mineral trioxide aggregate in teeth with immature apices," Journal of Endodontics, vol. 34, no. 7, pp. 812-817, 2008.

[3] A. P. Erdem and E. Sepet, "Mineral trioxide aggregate for obturation of maxillary central incisors with necrotic pulp and open apices," Dental Traumatology, vol. 24, no. 5, pp. e38-e41, 2008.

[4] P. E. Murray, F. Garcia-Godoy, and K. M. Hargreaves, "Regenerative endodontics: a review of current status and a call for action," Journal of Endodontics, vol. 33, no. 4, pp. 377-390, 2007.
[5] B. N. Östby, "The role of the blood clot in endodontic therapy. An experimental histologic study," Acta Odontologica Scandinavica, vol. 19, no. 3-4, pp. 323-353, 1961.

[6] R. Langer and J. P. Vacanti, “Tissue engineering," Science, vol. 260, no. 5110, pp. 920-926, 1993.

[7] G. T. Huang, S. Gronthos, and S. Shi, "Mesenchymal stem cells derived from dental tissues vs. those from other sources: their biology and role in regenerative medicine," Journal of Dental Research, vol. 88, no. 9, pp. 792-806, 2009.

[8] F. Banchs and M. Trope, "Revascularization of immature permanent teeth with apical periodontitis: new treatment protocol?” Journal of Endodontics, vol. 30, no. 4, pp. 196-200, 2004.

[9] S.-I. Iwaya, M. Ikawa, and M. Kubota, "Revascularization of an immature permanent tooth with apical periodontitis and sinus tract," Dental Traumatology, vol. 17, no. 4, pp. 185-187, 2001.

[10] M. Y.-H. Chen, K.-L. Chen, C.-A. Chen, F. Tayebaty, P. A. Rosenberg, and L. M. Lin, "Responses of immature permanent teeth with infected necrotic pulp tissue and apical periodontitis/abscess to revascularization procedures," International Endodontic Journal, vol. 45, no. 3, pp. 294-305, 2012.

[11] I.-Y. Jung, S.-J. Lee, and K. M. Hargreaves, "Biologically based treatment of immature permanent teeth with pulpal necrosis: a case series," Texas Dental Journal, vol. 129, no. 6, pp. 601-616, 2012.

[12] J. Camilleri and T. R. Pitt Ford, "Mineral trioxide aggregate: a review of the constituents and biological properties of the material," International Endodontic Journal, vol. 39, no. 10, pp. 747-754, 2006.

[13] A. Samara, Y. Sarri, D. Stravopodis, G. N. Tzanetakis, E. G. Kontakiotis, and E. Anastasiadou, "A comparative study of the effects of three root-end filling materials on proliferation and adherence of human periodontal ligament fibroblasts," Journal of Endodontics, vol. 37, no. 6, pp. 865-870, 2011.

[14] O. Trubiani, C. D’Arcangelo, D. Di Iorio, F. Di Nardo Di Maio, and S. Caputi, "Dental pulp stem cells bioadhesivity: evaluation on mineral-trioxide-aggregate," International Journal of Immunopathology and Pharmacology, vol. 20, no. 1, supplement 1, pp. 81-86, 2007.

[15] B. S. Chong, T. R. P. Ford, and M. B. Hudson, "A prospective clinical study of Mineral Trioxide Aggregate and IRM when used as root-end filling materials in endodontic surgery," International Endodontic Journal, vol. 42, no. 5, pp. 414-420, 2009.

[16] Q. Zhu, R. Haglund, K. E. Safavi, and L. S. W. Spangberg, "Adhesion of human osteoblasts on root-end filling materials," Journal of Endodontics, vol. 26, no. 7, pp. 404-406, 2000.

[17] T. Takita, M. Hayashi, O. Takeichi et al., "Effect of mineral trioxide aggregate on proliferation of cultured human dental pulp cells," International Endodontic Journal, vol. 39, no. 5, pp. 415-422, 2006

[18] S. Sartori, M. Silvestri, F. Forni, A. I. Cornaglia, P. Tesei, and V. Cattaneo, "Ten-year follow-up in a maxillary sinus augmentation using anorganic bovine bone (Bio-Oss). A case report with histomorphometric evaluation," Clinical Oral Implants Research, vol. 14, no. 3, pp. 369-372, 2003.

[19] K. A. Schlegel, G. Fichtner, S. Schultze-Mosgau, and J. Wiltfang, "Histologic findings in sinus augmentation with autogenous bone chips versus a bovine bone substitute," International Journal of Oral and Maxillofacial Implants, vol. 18, no. 1, pp. 5358, 2003. 
[20] A. Sculean, F. Schwarz, G. C. Chiantella et al., "Five-year results of a prospective, randomized, controlled study evaluating treatment of intra-bony defects with a natural bone mineral and GTR," Journal of Clinical Periodontology, vol. 34, no. 1, pp. 72-77, 2007.

[21] M. Piattelli, G. A. Favero, A. Scarano, G. Orsini, and A. Piattelli, "Bone reactions to anorganic bovine bone (Bio-Oss) used in sinus augmentation procedures: a histologic long-term report of 20 cases in humans," International Journal of Oral and Maxillofacial Implants, vol. 14, no. 6, pp. 835-840, 1999.

[22] G. Orsini, T. Traini, A. Scarano et al., "Maxillary sinus augmentation with Bio-Oss particles: a light, scanning, and transmission electron microscopy study in man," Journal of Biomedical Materials Research, Part B: Applied Biomaterials, vol. 74, no. 1, pp. 448-457, 2005.

[23] G. Weibrich, R. Trettin, S. H. Gnoth, H. Götz, H. Duschner, and W. Wagner, "Determining the size of the specific surface of bone substitutes with gas adsorption," Mund-, Kiefer- und Gesichtschirurgie, vol. 4, no. 3, pp. 148-152, 2000.

[24] L. Tronstad, "Tissue reactions following apical plugging of the root canal with dentin chips in monkey teeth subjected to pulpectomy," Oral Surgery, Oral Medicine, Oral Pathology, vol. 45, no. 2, pp. 297-304, 1978.

[25] R. Holland, M. J. Nery, V. Souza, P. F. E. Bernabé, W. Mello, and J. A. O. Filho, "The effect of the filling material in the tissue reactions following apical plugging of the root canal with dentin chips. A histologic study in monkeys' teeth," Oral Surgery, Oral Medicine, Oral Pathology, vol. 55, no. 4, pp. 398-401, 1983.

[26] H. K. Haapasalo, E. K. Sirén, T. M. T. Waltimo, D. Ørstavik, and M. P. P. Haapasalo, "Inactivation of local root canal medicaments by dentine: an in vitro study," International Endodontic Journal, vol. 33, no. 2, pp. 126-131, 2000.

[27] R. Rossmeisl, A. Reader, R. Melfi, and J. Marquard, "A study of freeze-dried (lyophilized) dentin used as an apical barrier in adult monkey teeth," Oral Surgery, Oral Medicine, Oral Pathology, vol. 53, no. 3, pp. 303-310, 1982.

[28] K. Petersson, G. Hasselgren, A. Petersson, and L. Tronstad, "Clinical experience with the use of dentine chips in pulpectomies," International Endodontic Journal, vol. 15, no. 4, pp. 161$167,1982$.

[29] R. J. Oswald and C. E. Friedman, "Periapical response to dentin filings. A pilot study," Oral Surgery, Oral Medicine, Oral Pathology, vol. 49, no. 4, pp. 344-355, 1980.

[30] A. Agrafioti, N. E. Tzimpoulas, and E. G. Kontakiotis, "Influence of dentin from the root canal walls and the pulp chamber floor on the $\mathrm{pH}$ of intracanal medicaments," Journal of Endodontics, vol. 39, no. 5, pp. 701-703, 2013.

[31] M. Torabinejad, R. Owen, R. A. Danforth, and R. E. Howell, "Periapical tissue responses to dentin and vitreous carbon plugs in apical perforations of dogs' teeth," Endodontics \& dental traumatology, vol. 1, no. 1, pp. 17-21, 1985.

[32] V. D’Antò, M. P. Di Caprio, G. Ametrano, M. Simeone, S. Rengo, and G. Spagnuolo, "Effect of mineral trioxide aggregate on mesenchymal stem cells," Journal of Endodontics, vol. 36, no. 11, pp. 1839-1843, 2010.

[33] E. P. Guven, M. E. Yalvac, F. Sahin, M. M. Yazici, A. A. Rizvanov, and G. Bayirli, "Effect of dental materials calcium hydroxidecontaining cement, mineral trioxide aggregate, and enamel matrix derivative on proliferation and differentiation of human tooth germ stem cells," Journal of Endodontics, vol. 37, no. 5, pp. 650-656, 2011.
[34] Q. Liu, T. Douglas, C. Zamponi et al., "Comparison of in vitro biocompatibility of NanoBone and BioOss for human osteoblasts," Clinical Oral Implants Research, vol. 22, no. 11, pp. 1259-1264, 2011.

[35] V. Sollazzo, A. Palmieri, L. Scapoli et al., "Bio-Oss®acts on Stem cells derived from Peripheral Blood," Oman Medical Journal, vol. 25, no. 1, pp. 26-31, 2010.

[36] S. Vahabi, N. Amirizadeh, M. A. Shokrgozar et al., "A comparison between the efficacy of bio-oss, hydroxyapatite tri calcium phosphate and combination of mesenchymal stem cells in inducing bone regeneration," Chang Gung Medical Journal, vol. 35, no. 1, pp. 28-37, 2012.

[37] M.-S. Seo, K.-G. Hwang, J. Lee, H. Kim, and S.-H. Baek, “The effect of mineral trioxide aggregate on odontogenic differentiation in dental pulp stem cells," Journal of Endodontics, vol. 39, no. 2, pp. 242-248, 2013.

[38] R. Haas, K. Donath, M. Födinger, and G. Watzek, "Bovine hydroxyapatite for maxillary sinus grafting: comparative histomorphometric findings in sheep," Clinical Oral Implants Research, vol. 9, no. 2, pp. 107-116, 1998.

[39] A. Rao and R. Shenoy, "Mineral trioxide aggregate-a review," Journal of Clinical Pediatric Dentistry, vol. 34 , no. 1, pp. 1-8, 2009. 

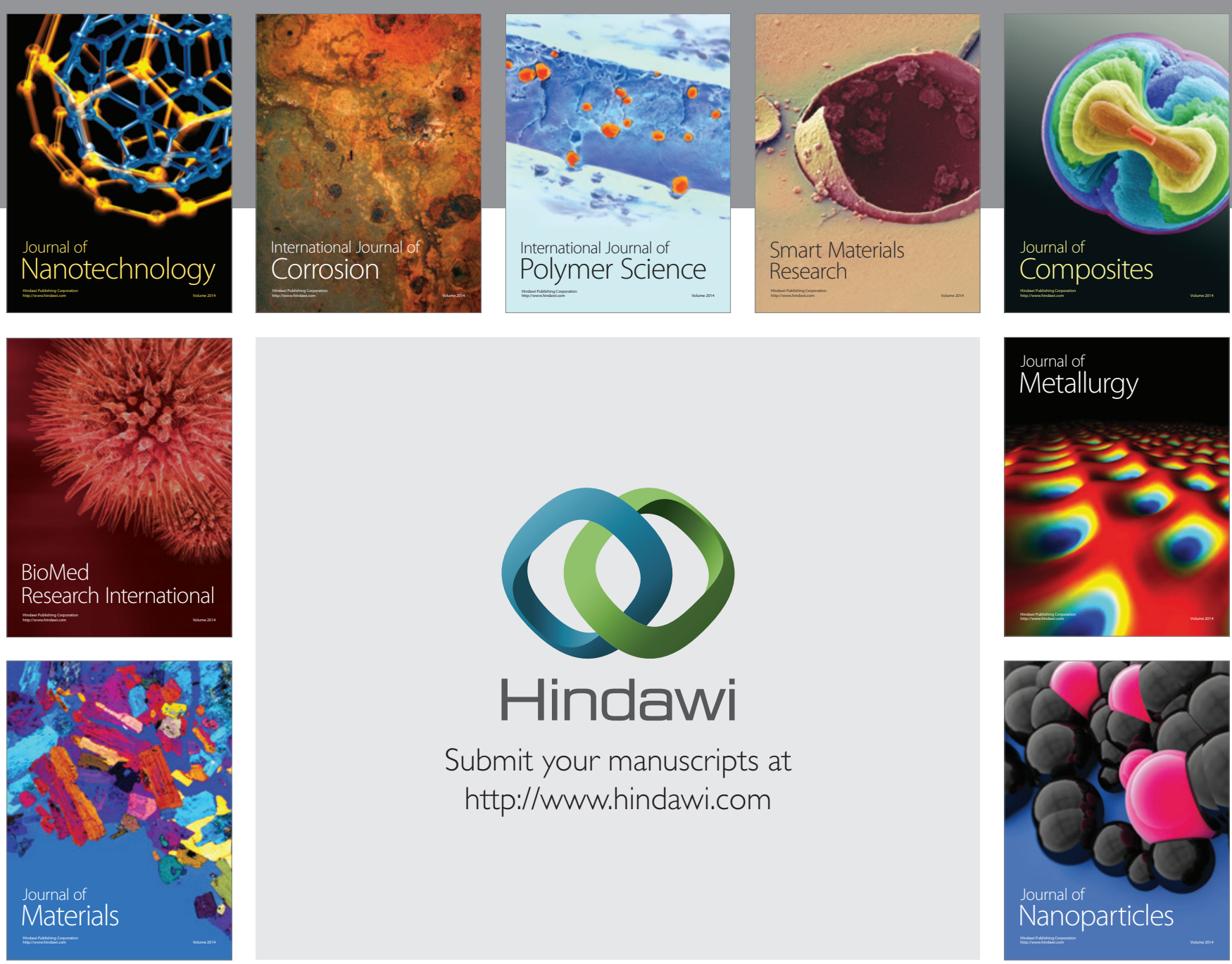

Submit your manuscripts at http://www.hindawi.com
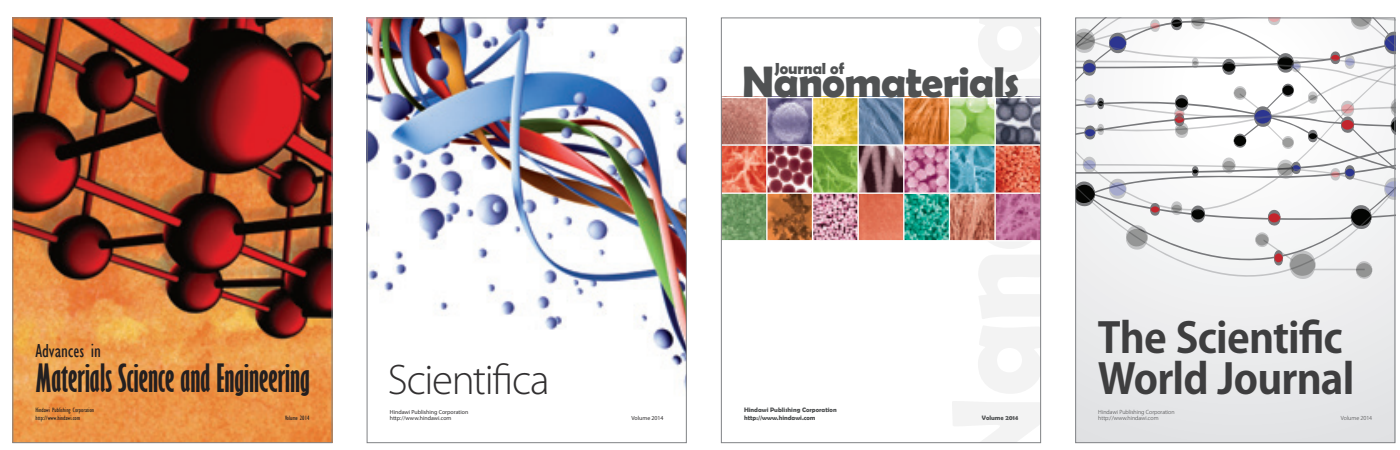

\section{The Scientific World Journal}
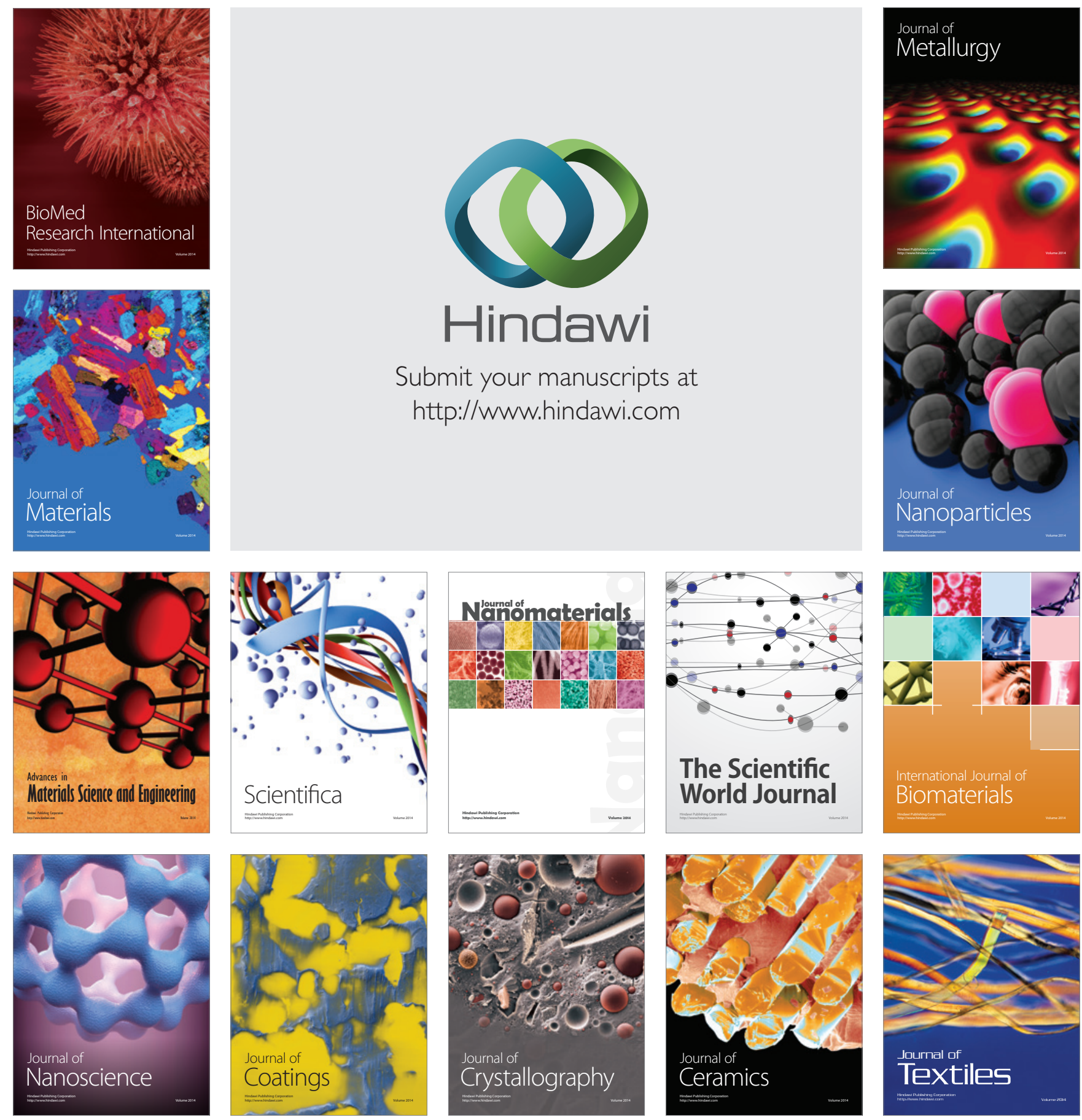